\title{
Obituary for Jamie Lee Hamilton, January 2020
}

\section{Becki Ross}

After a short, valiant battle with cancer, surrounded by loved ones, the legendary Jamie Lee Hamilton died at Cottage Hospice, in Vancouver, on December 23, 2019. Born in Vancouver on September 20, 1955, to Alice Hamilton (née McMillan) and Ralph Hamilton (both deceased), Jamie Lee is survived by her sister Gail Parker (Daniel Parker), nieces Tracy and Katherine, great nieces and nephews Nicholas, Caitlind, Justine, Crystal, and Andrew, and great great nieces and nephews Parker, Levi, and Elle. Growing up in East Vancouver, Jamie Lee attended Britannia high school and, later, Capilano University.

Nurturing friendships across diverse communities for five decades, Jamie Lee leaves behind a rich network of treasured kin, admirers, and political comrades. Identifying as Trans, Two Spirit, and Métis Cree, Jamie Lee had maternal roots in the Rocky Boy First Nation of Montana. Inspired by her parents' commitment to workers' rights, Jamie Lee dedicated her life to fighting for Indigenous people, sex workers, Two Spirit and LGBTQ+ individuals, and low-income residents of Vancouver's Downtown Eastside. A proud sex worker for almost fifty years, Jamie Lee was also an ingenious entrepreneur, fundraiser, and influencer. She operated community-based enterprises for trans and kink communities, including Rainbow's End, Queen's Cross, and Forbidden City. Jamie Lee was the first trans woman to run for political office in 1996. A gifted public intellectual, Jamie Lee educated thousands of undergraduates through lectures at the University of British Columbia, Simon Fraser University, and Douglas College. Jamie Lee co-founded, with Becki Ross, Canada's first and only Memorial for sex workers in her beloved West End. A mentor and mama to generations of queer, Two Spirit, trans, and Indigenous youth, Jamie Lee was respected for her kindness, mentorship, tenacity, and generosity of spirit. Her appetite for MAC cosmetics, Chinese cuisine, fish \& chips, glamorous fashion, community building, and radical social justice was epic.

Becki Ross, Professor

University of British Columbia

Jamie Lee Hamilton, whose work and legacy are discussed in the following keynote conversation between Dr. Viviane Namaste and Dalia Tourki, passed away on December 23, 2019. This obituary is reprinted with the permission of its author.

Canadian Journal of Law and Society / Revue Canadienne Droit et Société, 2020,

Volume 35, no. 2, pp. 157. doi:10.1017/cls.2020.23 